\title{
Gender Differences in the Association Between Obstructive Sleep Apnea and Diabetes
}

\author{
Ye Tao $\mathbb{D}^{1, *}$ \\ Xiaoli $\mathrm{Li}^{2, *}$ \\ Guang Yang' \\ Lingling Wang' \\ Junsong $\operatorname{Lian}^{3}$ \\ Zheng Chang'
}

'Central Medical District of Chinese PLA General Hospital, Beijing, People's Republic of China; ${ }^{2}$ The First Medical Center of Chinese PLA General Hospital, Beijing, 100853, People's Republic of China; ${ }^{3}$ The Second Medical Center of Chinese PLA General Hospital, Beijing, 100853, People's Republic of China

*These authors contributed equally to this work
Correspondence: Junsong Lian

The Second Medical Center of Chinese PLA General Hospital, 28 Fuxing Road, Beijing, 100853, People's Republic of China

Email148093109@qq.com

Zheng Chang

Central Medical District of Chinese PLA

General Hospital

Email cz780228@I63.com
Objective: This study aimed to explore the association between obstructive sleep apnea (OSA) and diabetes in a Chinese population based on a cross-sectional analysis of patient data from a large tertiary care hospital in China and analyses whether there are any gender differences in this association.

Methods: A total of 794 (615 men and 179 women) inpatients were involved in this study. Polysomnography (PSG) was used to diagnose OSA, and overnight PSG testing was performed on each subject included in this study. All study subjects were also diagnosed with whether they had diabetes by an endocrinologist in the hospital.

Results: After adjusting for sex, age, smoking status, alcohol consumption and body mass index (BMI) groups, the results showed that the number of apnea-hypopnea index (AHI) events was a risk factor for diabetes, with a $9 \%(95 \% \mathrm{CI}: 1-17 \%)$ increase in the risk of diabetes per unit increase, while subjects with higher (per unit increase) lowest oxygen saturation value monitored during the subject's sleep $\left(\mathrm{LSaO}_{2}\right)$ with a $13 \%(95 \% \mathrm{CI}$ : 4-22\%) decrease in the risk of diabetes. Stratified analyses by gender, after adjustment, in men, OSA and its associated monitoring indicators were statistically significantly associated with diabetes [OR for severe OSA was 2.269 (95\% CI: 1.164, 4.425), P=0.016, and OR for severe hypoxemia was 2.228 (95\% CI: $1.145,4.334), \mathrm{P}=0.018$ ], while not in women.

Conclusion: Our study found a significant association between OSA and diabetes in a Chinese clinical-based population as well as a dose-response relationship between the severity of AHI and severe hypoxemia $\left(\mathrm{LSaO}_{2}<80 \%\right)$ and blood glucose, the association has gender difference and was only present significant association in men, which demonstrated that diabetes prevention and blood glucose screening and management should be enhanced for Chinese men with OSA.

Keywords: obstructive sleep apnea, diabetes, gender differences, glucose, Chinese

\section{Introduction}

Diabetes is a metabolic disease, an independent risk factor for cardiovascular and cerebrovascular diseases. ${ }^{1}$ With the increase in the living standards of people in developing countries, diabetes incidence is increasing day by day and has become an epidemic chronic disease worldwide. ${ }^{2}$ According to the latest report, in 2019 , approximately 463 million adults aged 20-79 years worldwide had diabetes; it was expected to reach 700.2 million by 2045. IDF World Diabetes Map data of 2019 showed that China had the largest number of diabetic patients between the ages of 20-79 years, 116.4 (95\% CI: 108.6-145.7) million people, and it was expected to reach 147.2 (95\% CI:134.7-176.2) million in $2045 .^{3}$ In 2019, about 4.2 million people (aged 20-79 years) died of diabetes or its complications, equivalent to 
1 person every 8 seconds, accounting for about $11.3 \%$ of all-cause deaths globally. ${ }^{4}$ Type 2 diabetes mellitus (T2DM) is the most common type of diabetes.

Obstructive sleep apnea (OSA) is a highly prevalent respiratory disorder associated with sustained/intermittent reduction in blood oxygen saturation and tissue hypoxia, the prevalence in adults is between $35 \%$ and $58 \%{ }^{5}$ The disorder causes intermittent hypoxemia and hypercapnia, increased oxidative stress, inflammatory response, and sleep fragmentation. ${ }^{6}$ These signs and symptoms can further lead to cardiovascular disease, metabolic disease and even premature death. ${ }^{7-9}$ Intermittent hypoxemia and recurrent awakenings associated with sleep apnea may affect glucose through activation of the sympathetic nervous system, ${ }^{10}$ altered activity of the hypothalamic-pituitary-adrenal axis with increased circulating corticosteroid levels, ${ }^{11}$ increased inflammatory markers and adipocytederived factors. ${ }^{12}$ A number of recent studies have suggested that the increase in the prevalence of diabetes worldwide may be associated with the occurrence of OSA. ${ }^{13}$ Although studies on the association between OSA and diabetes have shown inconsistent results, ${ }^{14,15}$ a prospective analysis of 1453 non-diabetic participants showed that severe OSA was associated with greater risk of diabetes in the US population, ${ }^{14}$ while the results from the Wisconsin Sleep Cohort showed that the association between OSA and diabetes was not significant. ${ }^{15}$ Furthermore, some previous studies on the association have not adjusted for the influence of obesity, which is a common risk factor for OSA and diabetes. ${ }^{16}$ And the studies on the association between OSA and diabetes in the Chinese population were limited. Therefore, this study aimed to explore the association between OSA and diabetes in a Chinese population based on a cross-sectional analysis of patient data from a large tertiary care hospital in China, and analyses whether there are any gender differences in this association.

\section{Design and Methods Study Sample}

We used clinical data of all objectives from the Sleep Monitoring Unit, Chinese PLA General Hospital (a large tertiary hospital in China, Beijing) from August 2004 to December 2017.

We collected data regarding each participant's gender, age, alcohol and smoking consumption, diabetes and glucose status.

\section{Measurements}

T2DM was defined according to the American Diabetes Association criteria ${ }^{17}$ by endocrinologists in the hospital. That is T2DM is typically diagnosed when fasting plasma glucose (FPG) $\geq 7 \mathrm{mmol} / \mathrm{L}$ or 2 -h post oral glucose load plasma glucose $(2-\mathrm{h} P G) \geq 11.1 \mathrm{mmol} / \mathrm{L}$ or blood glucose $\geq 11.1 \mathrm{mmol} / \mathrm{L}$ at any time ${ }^{17}$ Blood glucose was analyzed using colorimetric method in a Modular P800 analyzer (Roche Diagnostics, Mannheim, Germany), and the unit of glucose was mmol/L. Polysomnography (PSG) is used to diagnose obstructive sleep apnea (OSA) and overnight PSG testing (from 10:00 p.m. to 7:00 a.m. and the sleep time is more than 7 hours) was performed on each subject included in this study. The PSG equipment model is EMBLA N7000. After automatic analysis of the original data, all corrections were manually verified. Two doctors who have worked in this field for more than 5 years provided a blinded interpretation of the objects' monitoring results. OSA was defined as the apnea-hypopnea index (AHI) $\geq 5$ times/h with typical symptoms associated with OSA, such as inability to rejuvenate after sleep, daytime drowsiness, fatigue or insomnia, wheezing on awakening, playing snoring very loudly or having apnea, etc.), or although there are no obvious symptoms, but $\mathrm{AHI} \geq 15$ times $/ \mathrm{h} .{ }^{18}$ Further, OSA patients were divided into a mild OSA group (AHI 5-15 times/h), a moderate OSA group (AHI 16-30 times/h), and a severe OSA group (AHI >30 times/h) according to the AHI. ${ }^{19}$ In overnight PSG testing, participants were defined as hypoxia when the lowest oxygen saturation $\left(\mathrm{LSaO}_{2}\right) \leq 90 \% .{ }^{20}$ According to the $\mathrm{LSaO}_{2}$, OSA patients were divided into a mild hypoxia group $\left(\mathrm{LSaO}_{2}\right.$ 86-90\%), a moderate hypoxia group $\left(\mathrm{LSaO}_{2} \quad 80-85 \%\right)$, and a severe hypoxia group $\left(\mathrm{LSaO}_{2}\right.$ $<80 \%)^{21}$

The included covariates include sex, age, smoking status, drinking status and body mass index (BMI). This information was collected by a trained primary nurse. An alcohol user was defined as a regular drinker who consumes alcohol almost every day and has been regularly consuming alcohol for more than six months. A former drinker was defined as having stopped regular alcohol consumption for more than six months. ${ }^{22}$ A current smoker was defined as a person who, at the time of the survey, smoked a tobacco product. A former smoker was defined as a person who had smoked daily for at least 6 months during their lives but at the time of the survey did not use a tobacco product. ${ }^{23} \mathrm{BMI}\left(\mathrm{Kg} / \mathrm{m}^{2}\right)$ is calculated as weight/ 
height $^{2}$. According to WHO Asian standards, subjects were divided into four groups by BMI: low body mass group (BMI $18.5 \mathrm{~kg} / \mathrm{m}^{2}$ ), normal group $\left(18.5 \mathrm{~kg} / \mathrm{m}^{2}\right.$ $\left.\leq \mathrm{BMI}<24.0 \mathrm{~kg} / \mathrm{m}^{2}\right)$, overweight group $\left(24 \mathrm{~kg} / \mathrm{m}^{2}\right.$ $\left.\leq \mathrm{BMI}<28.0 \mathrm{~kg} / \mathrm{m}^{2}\right)$ and obese group $\left(\mathrm{BMI} \geq 28.0 \mathrm{~kg} / \mathrm{m}^{2}\right) .{ }^{24}$

\section{Statistical Analysis}

SPSS version 26.0 was used for the data analysis. The significance level for all tests was set at a two-tailed $\alpha$ value of 0.05 . The differences in means and proportions were evaluated using Student's $t$-test and the chi-square test, respectively. Multiple linear regression models and logistic regression models were used to identify the association between OSA (including the indexes of OSA) and T2DM (including glucose).

\section{Ethical Considerations}

This study was conducted in accordance with the Declaration of Helsinki. And the committee for medical ethics of the Chinese PLA General Hospital examined and approved this study (No.S2017-327-03). Before completing the questionnaire, each involved participant signed an informed consent form.

\section{Results}

A total of 794 (615 men and 179 women) inpatients were involved in this study. The average age was $57.4 \pm 12.7$ years (range: 19-90 years). There were 277 objectives with diabetes and 517 without. The prevalence of T2DM was $34.9 \%(277 / 794)$ in this sample, and the prevalence was $32.5 \%(200 / 615)$ in men, $43.0 \%(77 / 179)$ in women. And there were 688 objectives diagnosed by PSG with OSA and 106 without. The average ages of those who with and without T2DM were $59.7 \pm 11.0$ years (range: $28-87$ years) and $56.2 \pm 13.3$ years (range: $19-90$ years), respectively. The general characteristics (age, gender, smoking status, drinking status and BMI) of the participants are shown in Table 1. Compared with the T2DM group, the group without T2DM was younger, had a higher proportion of men, had a lower mean number of AHI events, had a higher mean $\mathrm{LSaO}_{2}$, and had a higher proportion who never drank alcohol (Table $1, \mathrm{p}<0.05$ ).

Using T2DM (dichotomous variable) as the dependent variable, OSA and its related monitoring indicators were included in the equation as independent variables, respectively. After adjusting for sex, age, smoking status, alcohol consumption and BMI groups, the results showed that the number of AHI events was a risk factor for T2DM, with a $9 \%(95 \% \mathrm{CI}: 1-17 \%)$ increase in the risk of T2DM per unit increase, while subjects with higher (per unit increase) lowest oxygen saturation value monitored during the subject's sleep $\left(\mathrm{LSaO}_{2}\right)$ with a $13 \% \quad(95 \%$ CI: 4-22\%) decrease in the risk of T2DM (Table 2).

Stratified analyses by gender, after adjustment, in men, OSA and its associated monitoring indicators were statistically significantly associated with T2DM. Compared to men without OSA, the risk of T2DM in men with severe OSA (AHI $>30$ events $/ \mathrm{h})$ was 2.269 (95\% CI: 1.164, 4.425), $\mathrm{P}=0.016$, and the risk of T2DM in men with severe hypoxemia ( $\mathrm{LSaO} 2<80 \%$ ) was 2.228 (95\% CI: 1.145, 4.334), $\mathrm{P}=0.018$ (Table 2). In women, after adjustment, no statistically significant association was found between OSA/OSA associated monitoring indicators and T2DM (Table 2).

When glucose was involved in multiple linear regressions as a continuous outcome, OSA and its related monitoring indicators were included in the equation as independent variables, respectively. Models $\mathrm{A}$ to $\mathrm{C}$ showed that increased $\mathrm{LSaO}_{2}$ was associated with decreased glucose of the objectives after adjustment ( $\beta=-0.011,95 \% \mathrm{CI}:-0.021,-0.001$, $\mathrm{P}=0.029$, Table 3 ). In addition, after adjustment, in women, no significant association was found between OSA/OSArelated monitoring indicators and glucose, while in men, OSA severity was associated with glucose $(\beta=0.587,95 \%$ CI: $0.038-1.136, \mathrm{p}=0.036)$ and hypoxemia severity was also associated with glucose $(\beta=0.582,95 \%$ CI: $0.036-1.128$, $\mathrm{p}=0.037$ ) (Table 3).

\section{Discussion}

In this study, in a clinical-based Chinese population, we observed a significant association between OSA and T2DM as well as a dose-response relationship between the severity of AHI and hypoxemia and blood glucose, the association has gender difference and was only present in significant association in men.

Previous observational studies in both the $\mathrm{US}^{14}$ and Japanese populations $^{25}$ have shown a significant association between OSA and the development of T2DM, and the results were consistent with this study. However, most studies did not perform PSG monitoring to diagnose OSA in all included subjects, instead using home multilead monitoring or pulse oximetry to monitor nocturnal hypoxia and determine OSA status, and the studies reporting gender differences are limited.

Celen et $\mathrm{al}^{26}$ found that the contribution of OSA to diabetes development seems to be gender-dependent and 
Table I Sociodemographic Variables of the Participants

\begin{tabular}{|c|c|c|c|c|}
\hline & \multirow[t]{2}{*}{ Total } & \multirow{2}{*}{$\begin{array}{l}\text { Without T2DM } \\
(n=5 \mid 7)\end{array}$} & \multirow{2}{*}{$\begin{array}{l}\text { T2DM } \\
(n=277)\end{array}$} & \multirow[t]{2}{*}{$\mathbf{P}$} \\
\hline & & & & \\
\hline Age (years) & $57.4 \pm 12.7$ & $56.2 \pm 13.3$ & $59.7 \pm 11.0$ & $<0.001$ \\
\hline AHI (times/h) & $25.2 \pm 19.1$ & $24.1 \pm 18.4$ & $27.2 \pm 20.1$ & 0.027 \\
\hline $\mathrm{LSaO}_{2}$ & $74.9 \pm 16.0$ & $76.2 \pm 14.9$ & $72.5 \pm 17.5$ & 0.002 \\
\hline Gender & & & & 0.010 \\
\hline Female & 179 (22.5\%) & 102 (19.7\%) & 77 (27.8\%) & \\
\hline Male & 615 (77.5\%) & 415 (80.3\%) & $200(72.2 \%)$ & \\
\hline Age group & & & & $<0.001$ \\
\hline$<45$ ys & $113(14.2 \%)$ & 94 (I8.2\%) & 19 (6.9\%) & \\
\hline $45-64$ ys & $484(61.0 \%)$ & 307 (59.4\%) & 177 (63.9\%) & \\
\hline$\geq 65$ ys & $197(24.8 \%)$ & 116 (22.4\%) & $8 \mathrm{I}(29.2 \%)$ & \\
\hline BMI group & & & & 0.015 \\
\hline$<18.5 \mathrm{~kg} / \mathrm{m}^{2}$ & $5(0.6 \%)$ & $5(1.0 \%)$ & $0(0.0 \%)$ & \\
\hline $18.5-23.9 \mathrm{~kg} / \mathrm{m}^{2}$ & 90 (II.3\%) & $62(12.0 \%)$ & $28(10.1 \%)$ & \\
\hline $24.0-27.9 \mathrm{~kg} / \mathrm{m}^{2}$ & $322(40.6 \%)$ & 224 (43.3\%) & 98 (35.4\%) & \\
\hline$\geq 28.0 \mathrm{~kg} / \mathrm{m}^{2}$ & 377 (47.5\%) & 226 (43.7\%) & $15 \mathrm{I}(54.5 \%)$ & \\
\hline Smoking & & & & 0.057 \\
\hline Never & $416(52.4 \%)$ & $263(50.9 \%)$ & 153 (55.2\%) & \\
\hline Former & 151 (19.0\%) & $92(17.8 \%)$ & 59 (21.3\%) & \\
\hline Current & 227 (28.6\%) & $162(31.3 \%)$ & 65 (23.5\%) & \\
\hline Drinking & & & & 0.024 \\
\hline Never & 429 (54.0\%) & $263(50.9 \%)$ & 166 (59.9\%) & \\
\hline Former & 257 (32.4\%) & $184(35.6 \%)$ & 73 (26.4\%) & \\
\hline Current & $108(13.6 \%)$ & 70 (I3.5\%) & $38(13.7 \%)$ & \\
\hline OSA & & & & 0.276 \\
\hline No & $106(13.4 \%)$ & 74 (14.3\%) & 32 (11.6\%) & \\
\hline Yes & 688 (86.6\%) & 443 (85.7\%) & 245 (88.4\%) & \\
\hline OSA with hypoxemia & & & & 0.180 \\
\hline No & 134 (16.9\%) & 94 (I8.2\%) & 40 (14.4\%) & \\
\hline Yes & $660(83.1 \%)$ & $423(81.8 \%)$ & 237 (85.6\%) & \\
\hline $\mathrm{AHI}$ group & & & & 0.348 \\
\hline Without OSA & $106(13.4 \%)$ & 74 (I4.3\%) & $32(11.6 \%)$ & \\
\hline $5-15$ times $/ \mathrm{h}$ & $178(22.4 \%)$ & $12 \mid(23.4 \%)$ & $57(20.6 \%)$ & \\
\hline $16-30$ times/h & $205(25.8 \%)$ & $134(25.9 \%)$ & $7 \mathrm{l}(25.6 \%)$ & \\
\hline$>30$ times $/ \mathrm{h}$ & 305 (38.4\%) & $188(36.4 \%)$ & $117(42.2 \%)$ & \\
\hline Hypoxemia group & & & & 0.042 \\
\hline Without OSA & $106(13.4 \%)$ & $74(14.3 \%)$ & $32(11.6 \%)$ & \\
\hline$>85 \%$ & 185 (23.3\%) & $122(23.6 \%)$ & $63(22.7 \%)$ & \\
\hline $80-85 \%$ & $163(20.5 \%)$ & $117(22.6 \%)$ & $46(16.6 \%)$ & \\
\hline$<80 \%$ & $340(42.8 \%)$ & $204(39.5 \%)$ & $136(49.1 \%)$ & \\
\hline
\end{tabular}

only presents a significant association in women with an OR of 11.8. This inconsistency in the results may be due to the different study populations and the fact that although the study was a cohort study design, the diagnosis of OSA cases at baseline was not all made using the PSG method, the diagnosis of T2DM was also self-reported by patients 
Table 2 The Odds Ratios (ORs) for T2DM

\begin{tabular}{|c|c|c|c|c|c|c|}
\hline Exposure & Model A & $\mathbf{P}$ & Model B & $\mathbf{P}$ & Model C & $\mathbf{P}$ \\
\hline $\mathrm{AHI}$ (times/h) & $1.009(1.001,1.016)$ & 0.027 & $1.011(1.003,1.019)$ & 0.008 & $1.009(1.001,1.017)$ & 0.031 \\
\hline $\mathrm{LSaO}_{2}$ & $0.986(0.977,0.995)$ & 0.002 & $0.983(0.974,0.992)$ & 0.000 & $0.987(0.978,0.996)$ & 0.007 \\
\hline OSA & $1.279(0.82 \mathrm{I}, \mathrm{I} .992)$ & 0.276 & $1.316(0.834,2.079)$ & 0.238 & $1.312(0.834,2.064)$ & 0.240 \\
\hline OSA with hypoxemia & $1.317(0.880,1.970)$ & 0.181 & $1.365(0.902,2.064)$ & 0.141 & $\mathrm{I} .323(0.874,2.00 \mathrm{I})$ & 0.185 \\
\hline \multicolumn{7}{|l|}{ AHI group } \\
\hline Without OSA & I & & I & & I & \\
\hline $5-15$ times/h & $1.089(0.647,1.834)$ & 0.747 & $1.122(0.658,1.912)$ & 0.673 & $1.098(0.646,1.866)$ & 0.730 \\
\hline $16-30$ times $/ \mathrm{h}$ & $1.225(0.740,2.030)$ & 0.430 & $1.21 \mathrm{I}(0.722,2.031)$ & 0.468 & $1.264(0.756,2.113)$ & 0.372 \\
\hline$>30$ times $/ \mathrm{h}$ & $1.439(0.895,2.313)$ & 0.133 & $1.544(0.944,2.525)$ & 0.084 & $\mathrm{I} .502(0.922,2.447)$ & 0.103 \\
\hline \multicolumn{7}{|l|}{ Hypoxemia group } \\
\hline Without OSA & I & & I & & I & \\
\hline$>85 \%$ & $1.194(0.714,1.997)$ & 0.499 & I.187 $(0.699,2.014)$ & 0.525 & $1.298(0.766,2.198)$ & 0.332 \\
\hline $80-85 \%$ & $0.909(0.53 \mathrm{I}, \mathrm{I} .555)$ & 0.728 & $0.896(0.517,1.554)$ & 0.696 & $0.893(0.518,1.542)$ & 0.686 \\
\hline$<80 \%$ & $1.542(0.965,2.462)$ & 0.070 & $1.673(1.030,2.715)$ & 0.037 & $1.598(0.986,2.590)$ & 0.057 \\
\hline \multicolumn{7}{|l|}{ Male } \\
\hline $\mathrm{AHI}$ & $1.010(1.002,1.019)$ & 0.020 & $1.011(1.002,1.021)$ & 0.013 & $1.009(1.000,1.019)$ & 0.041 \\
\hline $\mathrm{LSaO}_{2}$ & $0.989(0.979,0.999)$ & 0.029 & $0.987(0.977,0.997)$ & 0.012 & $0.990(0.980,1.000)$ & 0.050 \\
\hline OSA & $2.061(1.094,3.880)$ & 0.025 & $2.035(1.075,3.853)$ & 0.029 & $2.017(1.063,3.826)$ & 0.032 \\
\hline OSA with hypoxemia & $1.981(1.144,3.433)$ & 0.015 & $2.001(1.150,3.484)$ & 0.014 & $1.962(1.121,3.431)$ & 0.018 \\
\hline \multicolumn{7}{|l|}{ AHI group } \\
\hline Without OSA & I & & I & & I & \\
\hline $5-15$ times $/ \mathrm{h}$ & I.872 $(0.925,3.79 I)$ & 0.081 & $\mathrm{I} .877(0.92 \mathrm{I}, 3.825)$ & 0.083 & $1.823(0.892,3.726)$ & 0.099 \\
\hline $16-30$ times $/ \mathrm{h}$ & $1.815(0.906,3.637)$ & 0.093 & $1.738(0.862,3.504)$ & 0.122 & $1.813(0.898,3.661)$ & 0.097 \\
\hline$>30$ times $/ \mathrm{h}$ & $2.335(1.208,4.5 \mid 3)$ & 0.012 & $2.340(1.203,4.553)$ & 0.012 & $2.269(1.164,4.425)$ & 0.016 \\
\hline \multicolumn{7}{|l|}{ Hypoxemia group } \\
\hline Without OSA & I & & I & & I & \\
\hline$>85 \%$ & $2.103(1.049,4.218)$ & 0.036 & $1.976(0.979,3.987)$ & 0.057 & $2.139(1.056,4.333)$ & 0.035 \\
\hline $80-85 \%$ & $1.563(0.757,3.230)$ & 0.228 & $1.516(0.728,3.158)$ & 0.267 & I.48I $(0.710,3.089)$ & 0.295 \\
\hline$<80 \%$ & $2.279(1.184,4.386)$ & 0.014 & $2.328(1.202,4.510)$ & 0.012 & $2.228(1.145,4.334)$ & 0.018 \\
\hline \multicolumn{7}{|l|}{ Female } \\
\hline AHI (times/h) & $1.010(0.993,1.026)$ & 0.246 & $1.007(0.990,1.024)$ & 0.420 & $1.010(0.992,1.028)$ & 0.296 \\
\hline $\mathrm{LSaO}_{2}$ & $0.962(0.937,0.986)$ & 0.003 & $0.961(0.936,0.986)$ & 0.002 & $0.966(0.942,1.001)$ & 0.051 \\
\hline OSA & $0.839(0.417,1.692)$ & 0.625 & $0.650(0.306,1.380)$ & 0.262 & $0.773(0.367,1.629)$ & 0.499 \\
\hline OSA with hypoxemia & $0.855(0.440,1.664)$ & 0.645 & $0.662(0.324,1.350)$ & 0.256 & 0.76 I (0.37।, I.559) & 0.455 \\
\hline \multicolumn{7}{|l|}{$\mathrm{AHI}$ group } \\
\hline Without OSA & I & & I & & I & \\
\hline $5-15$ times $/ \mathrm{h}$ & $0.558(0.226,1.375)$ & 0.205 & $0.432(0.168,1.110)$ & 0.081 & $0.514(0.200,1.319)$ & 0.166 \\
\hline $16-30$ times $/ \mathrm{h}$ & $0.980(0.425,2.26 \mathrm{I})$ & 0.962 & $0.76 \mid(0.3 \mid 5, I .839)$ & 0.545 & $0.895(0.37 I, 2.159)$ & 0.806 \\
\hline$>30$ times $/ \mathrm{h}$ & $0.986(0.43 \mathrm{I}, 2.258)$ & 0.974 & $0.766(0.319,1.840)$ & 0.552 & $0.957(0.391,2.344)$ & 0.924 \\
\hline
\end{tabular}


Table 2 (Continued).

\begin{tabular}{|c|c|c|c|c|c|c|}
\hline Exposure & Model A & $\mathbf{P}$ & Model B & $\mathbf{P}$ & Model C & $\mathbf{P}$ \\
\hline \multicolumn{7}{|l|}{ Hypoxemia group } \\
\hline Without OSA & I & & I & & I & \\
\hline$>85 \%$ & $0.556(0.221,1.398)$ & 0.212 & $0.446(0.169,1.174)$ & 0.102 & $0.572(0.216,1.512)$ & 0.260 \\
\hline $80-85 \%$ & $0.463(0.187,1.149)$ & 0.097 & $0.357(0.138,0.926)$ & 0.034 & $0.432(0.167,1.114)$ & 0.083 \\
\hline$<80 \%$ & I.575 (0.706, 3.5। 2$)$ & 0.267 & I.I $82(0.506,2.762)$ & 0.699 & $1.454(0.615,3.439)$ & 0.394 \\
\hline
\end{tabular}

Notes: Model A: crude model. Model B: adjusted for age and gender; Model C: adjusted for age, gender, smoking, drinking status and BMI.

Table 3 The Association Between OSA/OSA Related Monitoring Indicators and Glucose

\begin{tabular}{|c|c|c|c|c|c|c|}
\hline Exposure & Model A & $\mathbf{P}$ & Model B & $\mathbf{P}$ & Model C & $\mathbf{P}$ \\
\hline AHI (times/h) & $0.007(-0.001,0.016)$ & 0.077 & $0.009(0.000,0.017)$ & 0.042 & $0.006(-0.003,0.014)$ & 0.187 \\
\hline $\mathrm{LSaO}_{2}$ & $-0.014(-0.024,-0.004)$ & 0.005 & $-0.015(-0.025,-0.005)$ & 0.002 & $-0.01 \mathrm{I}(-0.02 \mathrm{I},-0.00 \mathrm{I})$ & 0.029 \\
\hline \multicolumn{7}{|l|}{ AHI GROUP } \\
\hline Without OSA & 0 & & 0 & & 0 & \\
\hline $5-15$ times $/ \mathrm{h}$ & $-0.055(-0.597,0.486)$ & 0.841 & $-0.003(-0.548,0.542)$ & 0.991 & $-0.078(-0.615,0.460)$ & 0.778 \\
\hline $16-30$ times $/ \mathrm{h}$ & $0.133(-0.395,0.661)$ & 0.621 & $0.175(-0.357,0.708)$ & 0.518 & $0.120(-0.404,0.643)$ & 0.654 \\
\hline$>30$ times $/ \mathrm{h}$ & $0.259(-0.239,0.757)$ & 0.308 & $0.331(-0.175,0.837)$ & 0.200 & $0.202(-0.295,0.700)$ & 0.426 \\
\hline \multicolumn{7}{|l|}{ Hypoxemia group } \\
\hline Without OSA & 0 & & 0 & & 0 & \\
\hline$>85 \%$ & $-0.026(-0.563,0.5 \mid 2)$ & 0.926 & $0.026(-0.517,0.570)$ & 0.925 & $0.021(-0.514,0.556)$ & 0.938 \\
\hline $80-85 \%$ & $-0.013(-0.563,0.538)$ & 0.964 & $0.006(-0.548,0.561)$ & 0.982 & $-0.065(-0.6 \mathrm{II}, 0.48 \mathrm{I})$ & 0.816 \\
\hline$<80 \%$ & $0.304(-0.187,0.795)$ & 0.225 & $0.379(-0.118,0.876)$ & 0.135 & $0.240(-0.253,0.733)$ & 0.340 \\
\hline OSA & $0.140(-0.320,0.601)$ & 0.551 & $0.194(-0.273,0.661)$ & 0.416 & $0.102(-0.356,0.56 \mathrm{I})$ & 0.661 \\
\hline OSA with hypoxemia & $0.222(-0.196,0.640)$ & 0.299 & $0.272(-0.151,0.695)$ & 0.208 & $0.163(-0.256,0.58 \mathrm{I})$ & 0.447 \\
\hline \multicolumn{7}{|l|}{ Male } \\
\hline AHI (times/h) & $0.011(0.003,0.020)$ & 0.008 & $0.012(0.003,0.020)$ & 0.007 & $0.009(0.001,0.018)$ & 0.036 \\
\hline $\mathrm{LSaO}_{2}$ & $-0.012(-0.021,-0.002)$ & 0.017 & $-0.012(-0.022,-0.003)$ & 0.012 & $-0.009(-0.019,0.001)$ & 0.070 \\
\hline \multicolumn{7}{|l|}{ AHI GROUP } \\
\hline Without OSA & 0 & & 0 & & 0 & \\
\hline $5-15$ times $/ \mathrm{h}$ & $0.402(-0.194,0.998)$ & 0.186 & $0.396(-0.199,0.992)$ & 0.193 & $0.351(-0.242,0.945)$ & 0.246 \\
\hline $16-30$ times $/ \mathrm{h}$ & $0.532(-0.052,1.116)$ & 0.075 & $0.509(-0.075,1.094)$ & 0.088 & $0.498(-0.082,1.077)$ & 0.093 \\
\hline$>30$ times $/ \mathrm{h}$ & $0.688(0.137,1.238)$ & 0.015 & $0.676(0.126,1.227)$ & 0.016 & $0.587(0.038,1.136)$ & 0.036 \\
\hline \multicolumn{7}{|l|}{ Hypoxemia group } \\
\hline Without OSA & 0 & & 0 & & 0 & \\
\hline$>85 \%$ & $0.455(-0.134,1.045)$ & 0.130 & $0.422(-0.168,1.012)$ & 0.161 & $0.462(-0.126,1.049)$ & 0.124 \\
\hline $80-85 \%$ & $0.454(-0.155,1.063)$ & 0.144 & $0.432(-0.178,1.042)$ & 0.166 & $0.374(-0.232,0.98 \mathrm{I})$ & 0.227 \\
\hline$<80 \%$ & $0.683(0.138,1.228)$ & 0.014 & $0.682(0.137,1.227)$ & 0.014 & $0.582(0.036,1.128)$ & 0.037 \\
\hline OSA & $0.572(0.052,1.091)$ & 0.031 & $0.558(0.039,1.077)$ & 0.036 & $0.502(0.015,1.018)$ & 0.047 \\
\hline OSA with hypoxemia & $0.543(0.083,1.003)$ & 0.021 & $0.539(0.079,0.999)$ & 0.022 & $0.46 \mathrm{I}(0.000,0.922)$ & 0.050 \\
\hline
\end{tabular}

(Continued) 
Table 3 (Continued).

\begin{tabular}{|c|c|c|c|c|c|c|}
\hline Exposure & Model A & $\mathbf{P}$ & Model B & $\mathbf{P}$ & Model C & $\mathbf{P}$ \\
\hline \multicolumn{7}{|l|}{ Female } \\
\hline $\mathrm{AHI}$ (times/h) & $-0.001(-0.024,0.022)$ & 0.935 & $0.002(-0.022,0.025)$ & 0.897 & $-0.004(-0.028,0.020)$ & 0.737 \\
\hline $\mathrm{LSaO}_{2}$ & $-0.031(-0.062,-0.001)$ & 0.046 & $-0.031(-0.062,-0.001)$ & 0.045 & $-0.025(-0.056,0.005)$ & 0.100 \\
\hline \multicolumn{7}{|l|}{ AHI GROUP } \\
\hline Without OSA & 0 & & 0 & & 0 & \\
\hline $5-15$ times/h & $-0.737(-1.997,0.524)$ & 0.254 & $-0.604(-1.900,0.691)$ & 0.362 & $-0.635(-1.85 I, 0.580)$ & 0.307 \\
\hline $16-30$ times $/ \mathrm{h}$ & $-0.359(-1.565,0.848)$ & 0.561 & $-0.235(-1.483,1.012)$ & 0.712 & $-0.278(-1.458,0.903)$ & 0.645 \\
\hline$>30$ times $/ \mathrm{h}$ & $-0.234(-1.429,0.962)$ & 0.702 & $-0.117(-1.357,1.122)$ & 0.853 & $-0.316(-1.499,0.867)$ & 0.601 \\
\hline \multicolumn{7}{|l|}{ Hypoxemia group } \\
\hline Without OSA & 0 & & 0 & & 0 & \\
\hline$>85 \%$ & $-0.786(-2.066,0.494)$ & 0.230 & $-0.706(-2.013,0.601)$ & 0.291 & $-0.692(-1.934,0.550)$ & 0.276 \\
\hline $80-85 \%$ & $-0.734(-1.973,0.505)$ & 0.247 & $-0.609(-1.886,0.668)$ & 0.351 & $-0.648(-1.848,0.552)$ & 0.291 \\
\hline$<80 \%$ & $0.026(-I .12 I, I .174)$ & 0.964 & $0.200(-0.996,1.396)$ & 0.744 & $0.015(-1.131,1.160)$ & 0.980 \\
\hline OSA & $-0.423(-1.428,0.582)$ & 0.411 & $-0.303(-1.356,0.750)$ & 0.573 & $-0.404(-1.386,0.578)$ & 0.421 \\
\hline OSA with hypoxemia & $-0.233(-1.188,0.72 I)$ & 0.632 & $-0.092(-1.098,0.915)$ & 0.858 & $-0.162(-1.109,0.786)$ & 0.738 \\
\hline
\end{tabular}

Notes: Model A: crude model. Model B: adjusted for age and gender; Model C: adjusted for age, gender, smoking, drinking status and BMI.

with mailed questionnaires rather than diagnosed in hospital by a medical professional, and the fact that the study included only 31 women, of whom 7 developed T2DM in self-reported follow-up, all of which may have contributed to the inconsistent results.

In the present study, a dose-response association was observed not only between the severity of OSA and its monitoring indicators $\left(\mathrm{AHI}\right.$ and $\mathrm{LSaO}_{2}$ ) for the risk of having T2DM but also between OSA and its monitoring indicators severity and blood glucose, independent of BMI and smoking and drinking habits. The association between OSA and blood glucose and the risk of having T2DM, independent of BMI, can be attributed to several possible mechanisms. For example, intermittent hypoxemia and recurrent awakenings associated with sleep apnea may affect glucose through activation of the sympathetic nervous system, ${ }^{27}$ altered activity of the hypothalamic-pituitary-adrenal axis with increased circulating corticosteroid levels, ${ }^{11}$ increased inflammatory markers (eg, hsCRP, interleukin-6, and tumor necrosis factor- $\alpha$ ) and adipocytederived factors (eg, leptin, adiponectin, and resistin). ${ }^{12}$

Previous study ${ }^{28}$ has suggested that a higher proportion of men in the patients with OSA and women with OSA tend to be more obese and older than men with OSA, which partly explains the failure to observe an association between OSA and T2DM independent of BMI in women in this study.
There were differences in fat distribution, upper airway length and collapse, neurochemical control mechanisms, chemical response levels, arousal responses and sex hormone effects between the sexes. ${ }^{29}$ Thus, men appear to be more susceptible to OSA than women because even with the same degree of obesity as women, men have a higher degree of peri-airway fat deposition, ${ }^{26,30}$ suggesting a difference in pathogenic mechanisms between men and women, which could partially explain the association between OSA and T2DM observed only in men in this study.

This study had several limitations. First, due to the inherent limitations of cross-sectional studies, we are unable to infer a causal association between OSA and T2DM, and subsequent rigorously designed cohort studies are needed to verify whether OSA treatment can have a beneficial effect on blood glucose levels by improving $\mathrm{AHI} / \mathrm{LSaO} 2$. Secondly, our sample may not be fully representative of OSA patients in China because our hospital is one of the best hospitals in China, and the proportion of patients here may differ from the proportion in other hospitals; however, the representativeness of our sample should not materially affect the internal validity of this study. Finally, we could not examine the hazard ratio of OSA with respect to T2DM because of the lack of detailed information regarding the onset time of OSA. 


\section{Conclusion}

In summary, our study found a significant association between OSA and T2DM in a Chinese clinical-based population, as well as a dose-response relationship between the severity of AHI and severe hypoxemia $\left(\mathrm{LSaO}_{2}<80 \%\right)$ and blood glucose, the association has gender difference and was only present significant association in men. Both OSA and T2DM are diagnosed professionally by a doctor in the hospital. We found that OSA may be a risk factor for T2DM in men; however, further cohort studies should be conducted to verify the causal relationship. Our findings demonstrated that T2DM prevention and blood glucose screening and management should be enhanced for Chinese men with OSA.

\section{Disclosure}

The authors report no conflicts of interest in this work.

\section{References}

1. Rydén L, Standl E, Bartnik M, Berghe G, Thrainsdottir I. [Guidelines on diabetes, pre-diabetes, and cardiovascular diseases]. Rev Esp Cardiol. 2007;60(5):1e-64e. Spanish

2. Whiting DR, Guariguata L, Weil C, Shaw J. IDF diabetes atlas: global estimates of the prevalence of diabetes for 2011 and 2030. Diabetes Res Clin Pract. 2011;94(3):0-321. doi:10.1016/j. diabres.2011.10.029

3. IDF. IDF diabetes atlas, 9th edition 2019; 2019. Available from: https://diabetesatlas.org/en/sections/individual-social-and-economicimpact.html. Accessed November 8, 2021.

4. Saeedi P, Salpea P, Karuranga S, et al. Mortality attributable to diabetes in 20-79 years old adults, 2019 estimates: results from the international diabetes federation diabetes atlas, 9(th) edition. Diabetes Res Clin Pract. 2020;162:108086. doi:10.1016/j. diabres.2020.108086

5. Wolters TLC, Roerink S, Drenthen LCA, et al. The course of obstructive sleep apnea syndrome in patients with acromegaly during treatment. $J$ Clin Endocrinol Metab. 2020;105(1):290-304. doi:10.1210/clinem/dgz050

6. Billings ME, Krishnan V, Su G, et al. Clinical practice guideline summary for clinicians: the role of weight management in the treatment of adult obstructive sleep apnea. Ann Am Thorac Soc. 2019;16 (4):405-408. doi:10.1513/AnnalsATS.201810-708CME

7. Group TSA. The relationship between obstructive sleep apnea and self-reported stroke or coronary heart disease in overweight and obese adults with type 2 diabetes mellitus. Sleep. 2012;9:1293-1298.

8. Tiberge M. Obstructive sleep apnea as a risk factor for stroke and death. China Prescription Drug. 2006;2(6):45.

9. Xu S, Wan Y, Xu M, et al. The association between obstructive sleep apnea and metabolic syndrome: a systematic review and meta-analysis. BMC Pulm Med. 2015;15(1):1-12.

10. Somers VK, White DP, Amin R, et al. Sleep apnea and cardiovascular disease: an American Heart Association/American College of cardiology foundation scientific statement from the American Heart Association council for high blood pressure research professional education committee, council on C. J Am Coll Cardiol. 2008;52 (8):686-717.
11. Henley DE, Russell GM, Douthwaite JA, et al. Hypothalamicpituitary-adrenal axis activation in obstructive sleep apnea: the effect of continuous positive airway pressure therapy. J Clin Endocrinol Metab. 2009;94(11):4234-4242. doi:10.1210/jc.2009-1174

12. Lavie L. Oxidative stress in obstructive sleep apnea and intermittent hypoxia-revisited-the bad ugly and good: implications to the heart and brain. Sleep Med Rev. 2015;20:27-45.

13. Reutrakul S, Mokhlesi B. Obstructive sleep apnea and diabetes: a state of the art review. Chest. 2017;152(5):1070-1086. doi:10.1016/j.chest.2017.05.009

14. Nagayoshi M, Punjabi NM, Selvin E, et al. Obstructive sleep apnea and incident type 2 diabetes. Sleep Med. 2016;25:156-161. doi:10.1016/j.sleep.2016.05.009

15. Reichmuth KJ, Austin D, Skatrud JB, Young T. Association of sleep apnea and type II diabetes: a population-based study. Am J Respir Crit Care Med.2005;172(12):1590-1595. doi:10.1164/rccm.200504-637OC

16. Tasali E, Mokhlesi B, Van Cauter E. Obstructive sleep apnea and type 2 diabetes: interacting epidemics. Chest. 2008;133(2):496-506. doi: $10.1378 /$ chest.07-0828

17. Power D. Standards of medical care in diabetes: response to position statement of the American Diabetes Association. Diabetes Care. 2006;29(2):S4-S36. doi:10.2337/diacare.29.02.06.dc05-1593

18. Kapur VK, Auckley DH, Chowdhuri S, et al. Clinical practice guideline for diagnostic testing for adult obstructive sleep apnea: an American Academy of Sleep Medicine Clinical Practice Guideline. J Clin Sleep Med. 2017;13(3):479-504. doi:10.5664/jcsm.6506

19. Culebras A. Double jeopardy: sleep apnea, atrial fibrillation and stroke. Sleep Med. 2015;30:255-256. doi:10.1016/j.sleep.2015.09.001

20. Catcheside PG, Stan OR, Chien CS, Jeremy M, Saunders NA, Mcevoy RD. Mild hypoxia does not suppress auditory arousal from NREM sleep. Sleep. 2006;5:619. doi:10.1093/sleep/29.5.619

21. Diseases SRDGotCMAoR. Guidelines for the management of obstructive sleep apnea hypoventilation syndrome (Trial). Chin J Intern Med. 2002;42(8):594-597.

22. Yang S, Shuang W, Bo Y, Zheng J, Cai Y, Yang Z. Alcohol consumption is a risk factor for lower extremity arterial disease in Chinese patients with T2DM. J Diabetes Res. 2017;2017:1-6. doi:10.1155/2017/3901392

23. Yang S, He Y, Liu M, et al. Changes in and patterns of smoking exposure in an elderly urban population in Beijing: 2001-2010. PLoS One. 2015;10(3):e0118500. doi:10.1371/journal.pone.0118500

24. Chen C, Lu FC. The guidelines for prevention and control of overweight and obesity in Chinese adults. Biomed Environ Sci. 2004;17 Suppl:1-36.

25. Muraki I, Tanigawa T, Yamagishi K, et al. Nocturnal intermittent hypoxia and the development of type 2 diabetes: the Circulatory Risk in Communities Study (CIRCS). Diabetologia. 2010;53(3):481-488. doi:10.1007/s00125-009-1616-0

26. Celen YT, Hedner J, Carlson J, Peker Y. Impact of gender on incident diabetes mellitus in obstructive sleep apnea: a 16-year follow-up. J Clin Sleep Med. 2010;6(3):244.

27. Li M, Li X, Lu Y. Obstructive sleep apnea syndrome and metabolic diseases. Endocrinology. 2018;159(7):2670-2675. doi:10.1210/ en.2018-00248

28. Jordan A, Mcevoy RD. Gender differences in sleep apnea: epidemiology, clinical presentation and pathogenic mechanisms. Sleep Med Rev. 2003;7(5):377-389. doi:10.1053/smrv.2002.0260

29. Buyse B, Markous N, Cauberghs M, Klaveren RV, Muls E, Demedts M. Effect of obesity and/or sleep apnea on chemosensitivity: differences between men and women. Respir Physiol Neurobiol. 2003;134(1):13-22. doi:10.1016/S1569-9048(02)00202-1

30. Chung F, Liao P, Yang Y, et al. Postoperative sleep-disordered breathing in patients without preoperative sleep apnea. Anesth Analg. 2015;120(6):1214-1224. doi:10.1213/ANE.0000000000000774 


\section{Publish your work in this journal}

Diabetes, Metabolic Syndrome and Obesity: Targets and Therapy is an international, peer-reviewed open-access journal committed to the rapid publication of the latest laboratory and clinical findings in the fields of diabetes, metabolic syndrome and obesity research. Original research, review, case reports, hypothesis formation, expert opinion and commentaries are all considered for publication. The manuscript management system is completely online and includes a very quick and fair peer-review system, which is all easy to use. Visit

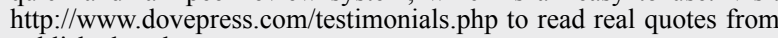
published authors. 